\title{
Frequency of metabolic syndrome and associated factors in institutionalized elderly individuals
}

This article was published in the following Dove Press journal:

Clinical Interventions in Aging

\section{Marcia Cristina Sales,' Larissa Praça Oliveira, ${ }^{2}$ Laura Camila Pereira Liberalino, ${ }^{3}$ Aline Tuane Oliveira Cunha, ${ }^{2}$ Sara Estefani Soares Sousa, ${ }^{4}$ Telma Maria Araujo Moura Lemos, ${ }^{5}$ Severina Carla Vieira Cunha Lima, ${ }^{6}$ Kenio Costa Lima, ${ }^{7}$ Karine Cavalcanti Mauricio Sena- Evangelista, ${ }^{6}$ Lucia Fatima Campos Pedrosa ${ }^{6}$ \\ 'Postgraduate Program of Health Sciences, Federal University of Rio Grande do Norte, Natal, Rio Grande do Norte, Brazil; ${ }^{2}$ School of Nutrition, Potiguar University (Laureate International Universities), Natal, Rio Grande do Norte, Brazil; ${ }^{3}$ Department of Medicine, State University of Rio Grande do Norte, Natal, Rio Grande do Norte, Brazil; ${ }^{4}$ Postgraduate Program of Nutrition, Federal University of Rio Grande do Norte, Natal, Rio Grande do Norte, Brazil; ${ }^{5}$ Department of Clinical and Toxicological Analysis, Federal University of Rio Grande do Norte, Natal, Rio Grande do Norte, Brazil; ${ }^{6}$ Department of Nutrition, Federal University of Rio Grande do Norte, Natal, Rio Grande do Norte, Brazil; ${ }^{7}$ Department of Dentistry, Federal University of Rio Grande do Norte, Natal, Rio Grande do Norte, Brazil}

Correspondence: Lucia Fatima Campos Pedrosa

Department of Nutrition, Federal University of Rio Grande do Norte, Avenida Senador Salgado Filho, 3000, Lagoa Nova, 59078970 Natal, Brazil Tel +55 843342229 I

Email Ifcpedrosa@gmail.com

\begin{abstract}
Introduction: Population aging generally accompanies an increase in chronic noncommunicable diseases, such as metabolic syndrome (MS). Nursing homes have provided a solution for the decreased ability of elderly individuals for self-care and familial difficulties in meeting the health care needs of elderly individuals.

Purpose: The aim of the present study was to determine the frequency of MS and its associated factors in elderly individuals living in nursing homes.

Patients and methods: This cross-sectional study was conducted with 202 institutionalized elderly individuals. MS was diagnosed according to the National Cholesterol Education Program - Adult Treatment Panel III criteria. Sociodemographic, clinical, and lifestyle factors were assessed to verify their association with MS by logistic regression.

Results: The MS frequency was 29.2\%. The most frequent MS components were low highdensity lipoprotein cholesterol level (63.9\%) and abdominal obesity (42.7\%). Factors associated with MS were female sex (prevalence ratio $[\mathrm{PR}]=2.16$; 95\% CI, 1.04-4.49), age-adjusted institutionalization time $>50 \%(\mathrm{PR}=2.38,95 \% \mathrm{CI}, 1.46-3.88)$, and high concentrations of interleukin-6 ( $\mathrm{PR}=2.01 ; 95 \% \mathrm{CI}, 1.21-3.32)$ and tumor necrosis factor- $\alpha(\mathrm{PR}=1.70 ; 95 \% \mathrm{CI}$, $1.05-2.77)$. Moreover, it was verified that the likelihood of having MS was 1.85 -fold higher (95\% CI, 1.11-3.10) in the group with a diet characterized by very high energy, very low fat, and high dietary fiber.

Conclusion: The occurrence of MS in institutionalized elderly individuals was higher in females, and individuals with longer age-adjusted institutionalization time, higher concentrations of immunologic biomarkers, and a dietary intake consisting of higher energy and fiber and lower total fat. The results of the study are useful for guiding health care programs aimed at institutionalized elderly individuals.
\end{abstract}

Keywords: chronic noncommunicable diseases, aging, nursing home, institutionalization

\section{Introduction}

Over the last few decades, declining birth and mortality rates have resulted in an increase in the proportion of elderly individuals worldwide. Population aging has changed the epidemiological profile of countries, with a greater prevalence of noncommunicable chronic diseases. Moreover, the demand for nursing homes (NHs) has increased due to elderly individuals' difficulty or dependency in carrying out activities, families' difficulties in meeting the health care needs of elderly members, and the associated costs. ${ }^{1}$ In Brazil, NH are governmental or nongovernmental institutions, of residential character, and aimed at fostering integral attention to the health of elderly individuals, including the aspects of promotion, protection, and prevention. ${ }^{2}$

Quality of the assistance depends on both the characteristics of the institutional system, in terms of structures and processes, and the standards of health professionals, 
including adequacy of training and education, and workload. However, unfavorable conditions in terms of physical structure, lifestyle, and human and care-related resources may contribute to the onset or aggravation of various health problems, ${ }^{3}$ including metabolic syndrome (MS). ${ }^{4}$

MS comprises at least three of the following components: abdominal obesity, hyperglycemia, arterial hypertension, hypertriglyceridemia, and low high-density lipoprotein cholesterol (HDL-c) level. We chose to use the criteria proposed by National Cholesterol Education Program - Adult Treatment Panel III (NCEP-ATP III) $)^{5}$ for simplicity and practicality, as recommended by the I Brazilian Guidelines on Diagnosis and Treatment of Metabolic Syndrome. ${ }^{6}$ The consensus of Brazilian medical societies recommends blood pressure and levels of triglycerides, the use of antihypertensive or lipid-lowering medications, and previous diagnosis of diabetes. The glycemia cutoff was changed to $\geq 100 \mathrm{mg} / \mathrm{dL}$, according to recommendations proposed by the American Diabetes Association. ${ }^{7}$

Despite the scarcity of studies and the variability of study findings resulting from the use of different diagnostic criteria, ${ }^{8}$ the frequency of MS is likely to be high among elderly individuals. In Brazil, only prevalence data of noninstitutionalized elderly individuals are available, with ranges of $22.3 \%-67.9 \% .^{9,10} \mathrm{~A}$ few studies on institutionalized elderly individuals have been carried out in Europe, Asia, and Oceania, with wide variations in the prevalence rates, diagnostic criterion, population studied, and sample size. ${ }^{11-16}$ The highest proportion of MS among institutionalized elderly individuals was observed in Indonesia $(57.6 \%),{ }^{16}$ while the lowest prevalence was reported in Croatia (20.8\%). ${ }^{4}$

The etiology of MS is multifactorial, including factors such as sex, age, low income, alcoholism, smoking, sedentary lifestyle, dietary inadequacy, and genetic predisposition. ${ }^{17,18}$ Alterations in the concentrations of inflammatory biomarkers are also thought to contribute to the development of MS, mostly in elderly individuals. ${ }^{19}$ Aging can compromise the immune system, increasing the synthesis of inflammatory mediators. High concentrations of interleukin (IL)-6, tumor necrosis factor (TNF)- $\alpha$, and C-reactive protein (CRP) are associated with the components of MS. ${ }^{19,20}$

A cohort study conducted with adults and elderly individuals showed that the likelihood of developing MS was 3.9-fold greater for people aged $\geq 45$ years, 2 .0-fold greater for males, 1.0-fold greater for those with a family history of diabetes mellitus, and 1.2-fold greater for individuals with a family history of arterial hypertension. ${ }^{18}$ Once established, it is estimated that MS doubles the risk of cardiovascular disease, such as myocardial infarction, stroke, and cardiovascular mortality, and increases all-cause mortality by $1.5-$ fold. ${ }^{21}$ Evidence also indicated that MS increases the risk of fragility by 1.85 -fold ${ }^{22}$ and can increase the risk of cognitive deficits, dementia, Alzheimer's disease, ${ }^{23}$ and depression. ${ }^{24}$

The identification of individuals with MS and its associated risk factors are useful in planning strategic interventions that can be implemented to reduce both the occurrence of this syndrome and its impact on population health. Although associated factors of MS have long been established, there are several shortcomings in the available literature regarding elderly individuals, especially the institutionalized population. Since scarce information is available regarding MS among the institutionalized elderly population, especially in Brazil, the present study was conducted to determine the frequency of MS and its association with sociodemographic, clinical, and lifestyle factors in institutionalized elderly individuals living in $\mathrm{NH}$.

\section{Patients and methods}

\section{Study design and population}

This analytical, cross-sectional study was conducted between November 2013 and April 2014. At the time of data collection, 393 elderly individuals were enrolled in $13 \mathrm{NH}$ from Natal city, which is located in the northeast of Brazil. Nine institutions agreed to participate in the study (304 individuals). All individuals at least 60 years old and living in these NHs were included. In Brazil, the National Health Surveillance Agency $^{2}$ and The Statute of Elderly (Law No. 10,741, of October 1, 2003) $)^{25}$ considers elderly individuals to be aged 60 years or older. Forty-seven individuals met the exclusion criteria such as venous access difficulty and incomplete data for the diagnosis of MS, 24 elderly individuals or their guardians refused to participate in the study, and 11 were lost due to death, internment, blood hemolysis, or outliers. Therefore, data collection was complete for 202 participants (Figure 1).

Participants were recruited through contact with $\mathrm{NH}$ directors, the elderly individuals themselves, and their families. Information explaining the objectives and steps of the research was provided. In the first stage, sociodemographic, clinical, and lifestyle data were collected from all study participants. Clinical data were collected by NH physicians from patient records or self-referrals, while sociodemographic and lifestyle information were obtained by other $\mathrm{NH}$ health professionals from records. A multidisciplinary team comprised physicians, nurses, physiotherapists, pharmacists, and nutritionists was responsible for compiling and documenting 


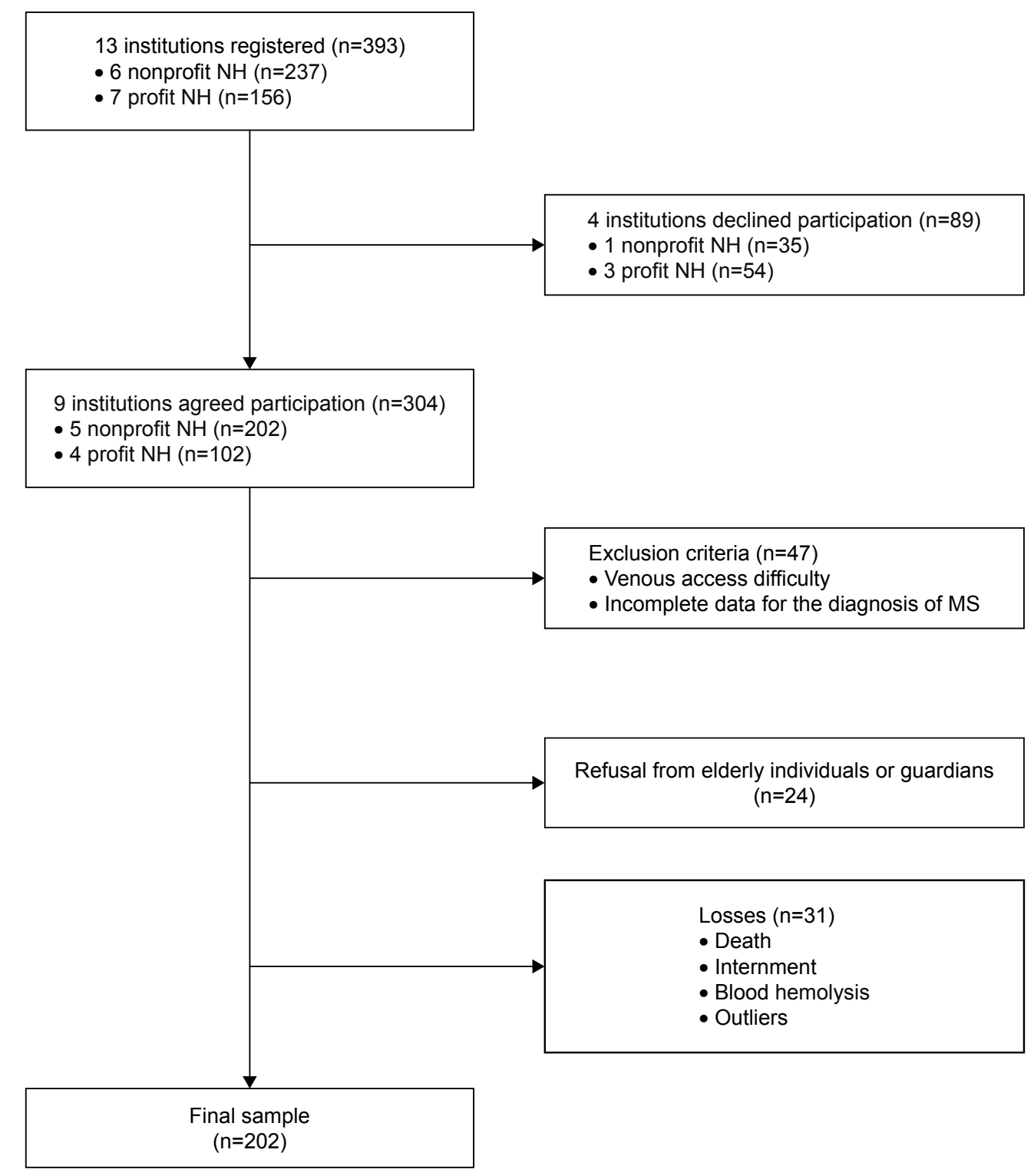

Figure I Flowchart of study participant selection.

Abbreviations: $\mathrm{NH}$, nursing home; MS, metabolic syndrome.

the information collected. All members of this team were trained in the use of the instruments used for data collection. The second stage of the research consisted of collecting anthropometric and food intake data and blood samples.

This study was approved by the Research Ethics Committee of the Federal University of Rio Grande do Norte (UFRN), Natal, Brazil, protocol 263/11; CAAE 0290.0.051.000-11. All participants or their guardians signed a free and informed consent form.

\section{Sociodemographic, clinical, and lifestyle variables}

Data concerning sex, age, type of institution, date of admission to the $\mathrm{NH}$, reason(s) for institutionalization, and institutionalization time were used to analyze the sociodemographic profiles of the participants. Institutionalization time was adjusted for age, considering that the age at which an individual was institutionalized would influence his/her health, according to the following formula: ${ }^{26,27}$

$$
\begin{aligned}
& \text { Age-adjusted institutionalization time } \\
& =\frac{\text { Data collection year }-\mathrm{NH} \text { admittance year }}{\text { Age in year }-60} \times 100
\end{aligned}
$$

Clinical variables included diabetes, arterial hypertension, and use of antihypertensive and hypoglycemic medications. Participants' lifestyles were evaluated using physical activity, alcohol intake, smoking, and smoking history variables. 


\section{Diagnosis of $\mathrm{MS}$}

For the purposes of this study, MS was diagnosed according to the National Cholesterol Education Program - Adult Treatment Panel III (NCEP-ATP III) criteria. ${ }^{5}$ At least three of the following criteria had to be present to diagnose MS: waist circumference $>102 \mathrm{~cm}$ for men and $>88 \mathrm{~cm}$ for women; triglyceride level $\geq 150 \mathrm{mg} / \mathrm{dL}$; HDL-c level $<40 \mathrm{mg} / \mathrm{dL}$ for men and $<50 \mathrm{mg} / \mathrm{dL}$ for women; systolic blood pressure $\geq 130 \mathrm{mmHg}$, diastolic blood pressure $\geq 85 \mathrm{mmHg}$, and/or use of antihypertensive drugs; and fasting blood glycemia $\geq 100 \mathrm{mg} / \mathrm{dL}$. The fasting blood glycemia cutoff was adjusted according to the American Diabetes Association guidelines $^{7}$ and/or use of oral hypoglycemic drugs. Waist circumference was measured at the midpoint between the last rib and the iliac crest using an inelastic tape measure. ${ }^{28}$ Blood pressure was measured as recommended by the VI Brazilian Guidelines on Hypertension. ${ }^{29}$

\section{Biochemical analysis}

Blood samples were collected via venipuncture after a 12-hour overnight fast. Blood glucose, triglycerides, and HDL-c levels were determined via colorimetric-enzymatic assays, using the Biochemical Analyzer Bio-200 (Barueri, Brazil) and kits from Labtest Diagnóstica ${ }^{\circledR}$ (Labtest Diagnóstica S.A., Lagoa Santa, Minas Gerais, Brazil). Immunologic analyses were conducted via chemiluminescence using an Immulite $1000^{\circledR}$ device (Malvern, PA, USA) with kits from Siemens ${ }^{\circledR}$ (Siemens Healthcare Diagnostics Products, Llanberis, Caernarfon, UK). The following cutoffs were adopted: $10.0 \mathrm{mg} / \mathrm{L}$ for high-sensitivity C-reactive protein, $8.1 \mathrm{pg} / \mathrm{mL}$ for TNF- $\alpha$, and $3.4 \mathrm{pg} / \mathrm{mL}$ for IL- 6 , according to the manufacturer's recommendations.

\section{Dietary intake assessment}

Food and dietary intake data were obtained by direct weighing of food. The quantity of food consumed (in grams) was determined based on the difference between the offered and rejected quantities. ${ }^{30}$ Data were collected on 2 separate days, with an interval of 30-45 days.

The dietary analysis was performed using Virtual Nutri Plus software, version 1.0. New preparations and foods, along with their nutritional composition, were added to the database as necessary. Energy intake was calculated from the average values obtained on both data collection days. Data on energy, total fat, and dietary fiber intake were grouped according to exploratory factorial analyses. The recommendations considered for percentage values of adequate protein and carbohydrate intake in relation to total energy were $15 \%$ and
$50 \%-60 \%$, respectively, according to the Acceptable Macronutrient Distribution Range ${ }^{31,32}$ and I Brazilian Guidelines on Diagnosis and Treatment of Metabolic Syndrome. ${ }^{6}$

\section{Statistical analysis}

The characteristics of the study participants are described using absolute and relative frequencies. The variables "main reasons for institutionalization," "smoking," "alcoholic beverage intake," "protein intake," and "carbohydrate intake" were excluded from the posterior analysis models because their frequency was $<10 \%$ in any category. The association between MS and sociodemographic, lifestyle, and immunologic biomarkers was assessed using the chi-squared test. The magnitude of the association was assessed using the prevalence ratio (PR) with the corresponding CIs, considered applicable for cross-sectional studies. ${ }^{33}$ The variables that demonstrated a statistically significant association with MS in the bivariate analysis model (sex, age-adjusted institutionalization time, IL-6, and TNF- $\alpha$ ) were tested in relation to each component of MS, using the chi-squared test. PR with the corresponding CI was also calculated. The variables associated with MS with a $P$-value $<0.20$ were analyzed by logistic regression for the construction of the multivariate model, utilizing the Stepwise Forward method. The permanence of the variable in the multiple analyses followed the Likelihood Ratio Test, absence of multicollinearity, as well as its ability to improve the model through the HosmerLemeshow test. Transformation from OR to PR followed Miettinen and Cook. ${ }^{34}$

Initially, the normality of data distribution for dietary intake was assessed using the Kolmogorov-Smirnov test. The results were then adjusted for energy. ${ }^{35}$ One-way ANOVA was used to determine intrapersonal variability, and estimates of intra- and interpersonal variances were based on the resulting quadratic means. ${ }^{36}$

For analysis of food intake, the distribution of dietary components, characterized by low variability of data and some categories with a value equal to zero, made it difficult to use the chi-squared test and calculate the PR using the raw data. In order to correct for low occurrence in categories such as macronutrients and dietary fiber, a factorial analysis was performed using the principal component analysis method. This analysis was used to better explain the data, since it allows for summarization under a common factor that reflects the concepts inherent to each food intake variable.

Therefore, food intake data were transformed into $z$-scores by presenting different units of measurements. The correlation matrix showed values $>0.85$ for proteins and 
Table I Factorial analysis model of the dietary components for institutionalized elderly individuals $(\mathrm{n}=\mathbf{1 7 8})$

\begin{tabular}{|c|c|c|c|c|c|c|}
\hline \multirow[t]{2}{*}{ Variables } & \multirow{2}{*}{$\begin{array}{l}\text { Values of } \\
\text { communalities }\end{array}$} & \multirow{2}{*}{$\begin{array}{l}\text { Factor load } \\
\text { values }\end{array}$} & \multicolumn{4}{|c|}{ Factor score quartiles } \\
\hline & & & $\begin{array}{l}\text { Group I } \\
\text { (up to }-0.68 \text { I) }\end{array}$ & $\begin{array}{l}\text { Group } 2 \\
(-0.680-0.109)\end{array}$ & \begin{tabular}{|l|} 
Group 3 \\
$(0.1 \mid 0-0.670)$
\end{tabular} & $\begin{array}{l}\text { Group } 4 \\
(>0.67 I)\end{array}$ \\
\hline Energy & 0.814 & 0.902 & Low & Moderate & High & Very high \\
\hline Total fat & 0.764 & -0.874 & High & Moderate & Low & Very low \\
\hline Dietary fiber & 0.327 & 0.572 & Very low & Low & Moderate & High \\
\hline
\end{tabular}

Note: Data were missing for 24 elderly individuals.

carbohydrates, which were excluded from the model and evaluated separately. Data for energy, total fat, and dietary fiber intake were grouped into a single factor, with a variance of $63.5 \%$. The commonality, factor load, and factor score values for each of the groups are shown in Table 1. Energy demonstrated greater commonality and factorial load, being the nutrient that best explains the factor. From the factorial scores obtained with the single factor, the participants were divided into four groups: Group 1: low energy, high fat, and very low dietary fiber intake; Group 2: moderate energy, moderate fat, and low dietary fiber intake; Group 3: high energy, low fat, and moderate dietary fiber intake; and Group 4: very high energy, very low fat, and high dietary fiber intake. These groups were obtained from the quartiles of the factorial scores. In the classification of the groups, the progressive increase in factorial score quartiles implied a progressive increase in energy and dietary fiber intake (as this increase was more indicative of energy rather than dietary fiber due to the factorial load) and a reduction in total fat intake. Statistical significance was set at $P<0.05$. All data analyses were performed using IBM SPSS version 20.0 (IBM Corporation, Armonk, NY, USA).

\section{Results}

MS was diagnosed in $29.2 \%$ (95\% CI, $23.0 \%-36.0 \%)$ of the elderly individuals. Low HDL-c was the most frequently observed MS component (63.9\%), while all other components affected $<50 \%$ of the population. The mean age was high (82.0 \pm 9.1 years), and the overall population demonstrated a high proportion of women and individuals residing at nonprofit institutions. Lack of caregiver was the main reason for institutionalization, reported by $35.8 \%$ of the individuals, while the "own option" alternative was cited by only $6.7 \%$ of the participants. Thus, more than half of the participants remained institutionalized for up to $25 \%$ of their elderly lifetime. Concerning lifestyle habits, approximately three-fourth of the population was considered to be sedentary. On the other hand, three-fourth had never smoked, and the majority of the individuals were current nonsmokers (90.8\%) and did not consume alcohol (97.0\%). High carbohydrate and protein diet intake was verified, with low variability among the data, especially protein intake, and almost all participants were included in the category "above recommended." When evaluating the quality of the diet of the elderly individuals according to the categorization of the groups constituted according to composition of energy and nutrients, we observed similar percentages of individuals distributed among the higher (Groups 1 and 2) and lower risk groups (Groups 3 and 4). Almost all the individuals (97.8\%) presented concentrations of high-sensitivity C-reactive protein (hs-CRP) above the normality parameters, which indicates a population with an intense inflammatory profile. The proportion of participants that had abnormally high concentrations of IL- 6 and TNF- $\alpha$ was $47.5 \%$ and $44.6 \%$, respectively (Table 2 ).

The frequency of MS was greater in females, individuals who spent $>50 \%$ of their elderly lifetime in $\mathrm{NH}$, and elderly individuals with high concentrations of IL- 6 and TNF- $\alpha$ (all $P<0.05)$. Age, type of institution, lifestyle, and diet were not associated with the occurrence of MS $(P>0.05)$ (Table 3).

Variables significantly associated with MS were tested in relation to the MS components. Females had a higher occurrence of low HDL-c $(P=0.017)$ and abdominal obesity $(P=0.003)$. An age-adjusted institutionalization time of $25 \%-50 \%$ was associated with increase in the occurrence of hypertriglyceridemia $(P=0.018)$ and arterial hypertension $(P=0.024)$ in individuals with $>50 \%$ of their elderly lifetime in NH. IL-6 concentrations were higher in those with abdominal obesity $(P<0.001)$ and low HDL-c concentrations $(P=0.020)$. Furthermore, a high concentration of TNF- $\alpha$ was associated with increased hypertriglyceridemia $(P<0.001)$ and low HDL-c concentrations $(P<0.001)$. Among the components of MS, low HDL-c presented the most statistically significant association with risk factors. Hyperglycemia was the only component that presented no statistically significant association with any of the risk factors analyzed (Table 4).

The logistic regression model confirmed the statistical significance observed in the bivariate model between MS 
Table 2 Frequency of MS and MS components, and sociodemographic, clinical, and lifestyle factors among institutionalized elderly individuals $(n=202)$

\begin{tabular}{|c|c|}
\hline Characteristic & n (\%) \\
\hline \multicolumn{2}{|l|}{ MS } \\
\hline Yes & $59(29.2)$ \\
\hline No & $143(70.8)$ \\
\hline \multicolumn{2}{|l|}{ MS components } \\
\hline Abdominal obesity & $82(42.7)$ \\
\hline Hyperglycemia and/or use of oral hypoglycemic drugs & $52(25.7)$ \\
\hline $\begin{array}{l}\text { Arterial hypertension and/or use of antihypertensive } \\
\text { drugs }\end{array}$ & $80(40.2)$ \\
\hline Hypertriglyceridemia & $38(18.8)$ \\
\hline Low HDL-c & $129(63.9)$ \\
\hline \multicolumn{2}{|l|}{ Sex } \\
\hline Male & $50(24.8)$ \\
\hline Female & $152(75.2)$ \\
\hline \multicolumn{2}{|l|}{ Age (years) } \\
\hline$<75$ & $48(23.8)$ \\
\hline$\geq 75$ & $154(76.2)$ \\
\hline \multicolumn{2}{|l|}{ Type of nursing home } \\
\hline Nonprofit & $14 \mid(69.8)$ \\
\hline For profit & $61(30.2)$ \\
\hline \multicolumn{2}{|l|}{ Main reason for institutionalization } \\
\hline Lack of caregiver & $69(35.8)$ \\
\hline Disease & $38(19.7)$ \\
\hline Living alone & $29(15.0)$ \\
\hline Lack of housing & $20(10.4)$ \\
\hline Own option & $13(6.7)$ \\
\hline Other options & $24(12.4)$ \\
\hline \multicolumn{2}{|l|}{ Age-adjusted institutionalization time (\%) } \\
\hline$<25$ & $115(56.9)$ \\
\hline $25-50$ & $48(23.8)$ \\
\hline$>50$ & $39(19.3)$ \\
\hline \multicolumn{2}{|l|}{ Physical activity } \\
\hline Yes & $51(26.7)$ \\
\hline No & $140(73.3)$ \\
\hline \multicolumn{2}{|l|}{ Smoking } \\
\hline Yes & $18(9.2)$ \\
\hline No & $178(90.8)$ \\
\hline \multicolumn{2}{|l|}{ Former smoking } \\
\hline Yes & $40(25.6)$ \\
\hline No & $116(74.4)$ \\
\hline \multicolumn{2}{|l|}{ Alcoholic beverage intake } \\
\hline Yes & $6(3.0)$ \\
\hline No & $191(97.0)$ \\
\hline \multicolumn{2}{|l|}{ Carbohydrate intake (\% total energy) } \\
\hline Below recommended & II (6.2) \\
\hline Recommended & $79(44.4)$ \\
\hline Above recommended & $88(49.4)$ \\
\hline \multicolumn{2}{|l|}{ Protein intake (\% total energy) } \\
\hline Below recommended & $4(2.2)$ \\
\hline Above recommended & $174(97.8)$ \\
\hline \multicolumn{2}{|l|}{ Energy, total fat, and dietary fiber intake ${ }^{a}$} \\
\hline Group I & $44(24.7)$ \\
\hline Group 2 & $46(25.8)$ \\
\hline Group 3 & $44(24.7)$ \\
\hline Group 4 & $44(24.7)$ \\
\hline
\end{tabular}

Table 2 (Continued)

\begin{tabular}{l|l}
\hline Characteristic & $\mathbf{n}(\%)$ \\
\hline hs-CRP $(\mathrm{mg} / \mathrm{dL})$ & \\
$\quad \geq 10.0$ & $20 \mathrm{I}(99.5)$ \\
$\quad<10.0$ & $\mathrm{I}(0.5)$ \\
$\mathrm{IL}-6(\mathrm{pg} / \mathrm{mL})$ & \\
$\geq 3.4$ & $96(47.5)$ \\
$<3.4$ & $\mathrm{I} 06(52.5)$ \\
TNF- $\alpha(\mathrm{pg} / \mathrm{mL})$ & \\
$\geq 8.1$ & $90(44.6)$ \\
$<8 . \mathrm{I}$ & $\mathrm{II} 2(55.4)$ \\
\hline
\end{tabular}

Notes: Data are expressed as $n$ (\%). Data were missing for abdominal obesity $(n=10)$; arterial hypertension and/or use of antihypertensive drugs $(n=3)$; main reason for institutionalization ( $n=9)$; physical activity $(n=11)$; smoking $(n=6)$; former smoking $(n=46)$; alcoholic beverage intake $(n=5)$; energy, total fat, and dietary fiber intake $(n=24)$; carbohydrate intake (\% total) $(n=24)$; and protein intake (\% total)

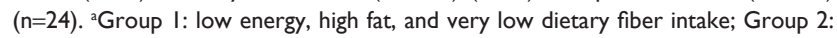
moderate energy, moderate fat, and low dietary fiber intake; Group 3: high energy, low fat, and moderate dietary fiber intake; Group 4: very high energy, very low fat, and high dietary fiber intake.

Abbreviations: HDL-c, high-density lipoprotein cholesterol; hs-CRP, highsensitivity C-reactive protein; IL, interleukin; TNF, tumor necrosis factor; MS, metabolic syndrome.

and the independent variables of sex, age-adjusted institutionalization time, IL-6, and TNF- $\alpha$ (all $P<0.05$ ). Moreover, it was verified that the likelihood of diagnosis of MS was greater in individuals in Group 4 (very high energy, very low fat, and high dietary fiber intake) than in individuals in Group 2 (moderate energy, moderate fat, and low dietary fiber intake) $(P=0.019)$ (Table 5).

\section{Discussion}

There was a moderate frequency of MS among elderly individuals. The frequency of MS was higher in participants who were female, and in individuals with an age-adjusted institutionalization time $>50 \%$ of their elderly lifetime, high IL- 6 and TNF- $\alpha$ levels, and a dietary intake consisting of higher energy and fiber and lower total fat. MS frequency was similar to that reported in a study conducted among an institutionalized elderly population in Taiwan (29.1\%), ${ }^{14}$ and lower than that reported for individuals residing in $\mathrm{NH}$ in Indonesia (57.6\%). ${ }^{16} \mathrm{~A}$ systematic review of Brazilian adults indicated a significant increase in the risk for MS with advancing age. ${ }^{9}$ It is estimated that $47.9 \%-50.3 \%$ of Brazilian elderly individuals have MS, without any specific data for institutionalized elderly individuals. ${ }^{9,10}$ The variability of prevalence data can be attributed to specific behavioral and epidemiological patterns of countries and populations. ${ }^{10}$ The analysis of the prevalence of MS has also been hampered by the lack of consensus on its definition and the cutoffs used for its respective components. ${ }^{9}$ Despite this, it is speculated that a high prevalence of MS in elderly individuals 
Table 3 Association between MS in institutionalized elderly individuals, and sociodemographic, lifestyle, and clinical variables with $\mathrm{n}$ percent values $>10(n=202)$

\begin{tabular}{|c|c|c|c|}
\hline & Individuals with MS, n (\%) & PR (95\% Cl) & $P$-value ${ }^{a}$ \\
\hline \multicolumn{4}{|l|}{ Sex } \\
\hline Male $(n=50)$ & $8(16.0)$ & 1.00 & 0.016 \\
\hline Female $(n=152)$ & $51(33.6)$ & $2.35(1.14-4.83)$ & \\
\hline \multicolumn{4}{|l|}{ Age (years) } \\
\hline$\leq 75(n=48)$ & $18(37.5)$ & $1.43(0.91-2.25)$ & 0.183 \\
\hline$>75(n=154)$ & $41(26.6)$ & 1.00 & \\
\hline \multicolumn{4}{|l|}{ Type of nursing home } \\
\hline Nonprofit $(n=|4|)$ & $40(28.4)$ & 1.00 & 0.761 \\
\hline Profit $(n=61)$ & $19(31.1)$ & I.I2 (0.7I-I.77) & \\
\hline \multirow{2}{*}{\multicolumn{4}{|c|}{$\begin{array}{l}\text { Age-adjusted institutionalization } \\
\text { time (\%) }\end{array}$}} \\
\hline & & & \\
\hline$<25(\mathrm{n}=115)$ & $29(50.0)$ & $1.32(0.68-2.56)$ & 0.533 \\
\hline $25-50(n=48)$ & $9(15.5)$ & 1.00 & - \\
\hline$>50(n=39)$ & $20(34.5)$ & $2.68(1.38-5.19)$ & 0.004 \\
\hline \multicolumn{4}{|l|}{ Physical activity, $n=\mid 91$} \\
\hline Yes $(n=5 I)$ & $15(29.4)$ & $1.00(0.59-1.61)$ & 1.000 \\
\hline No $(n=140)$ & $4 \mathrm{I}(29.3)$ & 1.00 & \\
\hline \multicolumn{4}{|l|}{ Former smoking, $n=156$} \\
\hline Yes $(n=40)$ & $13(32.5)$ & I.II (0.65-I.88) & 0.858 \\
\hline No $(n=116)$ & $34(29.3)$ & 1.00 & \\
\hline \multirow{2}{*}{\multicolumn{4}{|c|}{ 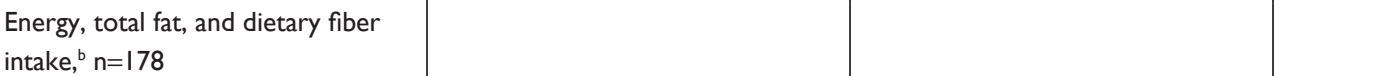 }} \\
\hline & & & \\
\hline Group I $(n=44)$ & $13(29.5)$ & $1.28(0.62-2.66)$ & 0.669 \\
\hline Group $2(n=46)$ & $10(21.7)$ & 1.00 & - \\
\hline Group $3(n=44)$ & $12(27.3)$ & $1.25(0.60-2.60)$ & 0.715 \\
\hline Group $4(n=44)$ & $18(40.9)$ & $1.88(0.98-3.62)$ & 0.083 \\
\hline \multicolumn{4}{|l|}{ IL-6 (pg/mL) } \\
\hline$\geq 3.4(n=96)$ & $39(40.6)$ & $2.25(1.40-3.60)$ & 0.001 \\
\hline$<3.4(\mathrm{n}=106)$ & $20(18.9)$ & 1.00 & \\
\hline \multicolumn{4}{|l|}{ TNF- $\alpha(\mathrm{pg} / \mathrm{mL})$} \\
\hline$\geq 8.1 \quad(n=90)$ & $34(37.8)$ & $1.75(1.12-2.72)$ & 0.018 \\
\hline$<8.1(\mathrm{n}=\mid \mathrm{I})$ & $25(22.3)$ & 1.00 & \\
\hline
\end{tabular}

Notes: Data are expressed as n (\%). ${ }^{\mathrm{a} C h i}$-squared test. ${ }^{\mathrm{b}} \mathrm{Group}$ I: low energy, high fat, and very low dietary fiber intake; Group 2: moderate energy, moderate fat, and low dietary fiber intake; Group 3: high energy, low fat, and moderate dietary fiber intake; Group 4: very high energy, very low fat, and high dietary fiber intake.

Abbreviations: IL, interleukin; MS, metabolic syndrome; PR, prevalence ratio; TNF, tumor necrosis factor.

exists due to the functional and metabolic changes resulting from aging. ${ }^{7}$ Thus, institutionalized elderly individuals are more susceptible to health problems due to the burden of comorbidity, frailty, and disability. ${ }^{1}$

Moreover, in the present study, the most frequent MS components observed were low HDL-c level, abdominal obesity, and arterial hypertension. Similar results were reported in research conducted among noninstitutionalized elderly individuals in Brazil ${ }^{37}$ and Turkey. ${ }^{38}$ Studies focusing on MS and its components enable stratification of individuals according to risk levels and allow for suitable treatment for each component, in order to reduce morbidity and mortality associated with this condition. ${ }^{21,39}$ Pharmacologic treatment and dietary modifications, including lowering intake of saturated fats, trans fats, cholesterol, sodium, and simple sugars, are known to alleviate dyslipidemia, hyperglycemia, and arterial hypertension. ${ }^{40}$ In addition, physical activity has positive impacts on physical fitness in frail individuals ${ }^{1}$ and weight reduction. ${ }^{40}$

When evaluating factors associated with MS and its components, we observed a higher frequency of abdominal obesity and low HDL-c concentrations in women compared with men. Similar findings have been observed among noninstitutionalized elderly individuals in other regions of Brazil ${ }^{37,41}$ and among institutionalized elderly individuals in other countries. ${ }^{4,15}$ These findings can be linked to menopausal hormonal alterations that result in a greater deposition of abdominal fat and an unfavorable lipid profile. ${ }^{42,43}$ Menopause is associated with a $60 \%$ risk of MS development. ${ }^{43}$ Visceral fat is more sensitive to lipolysis, a process that generates 


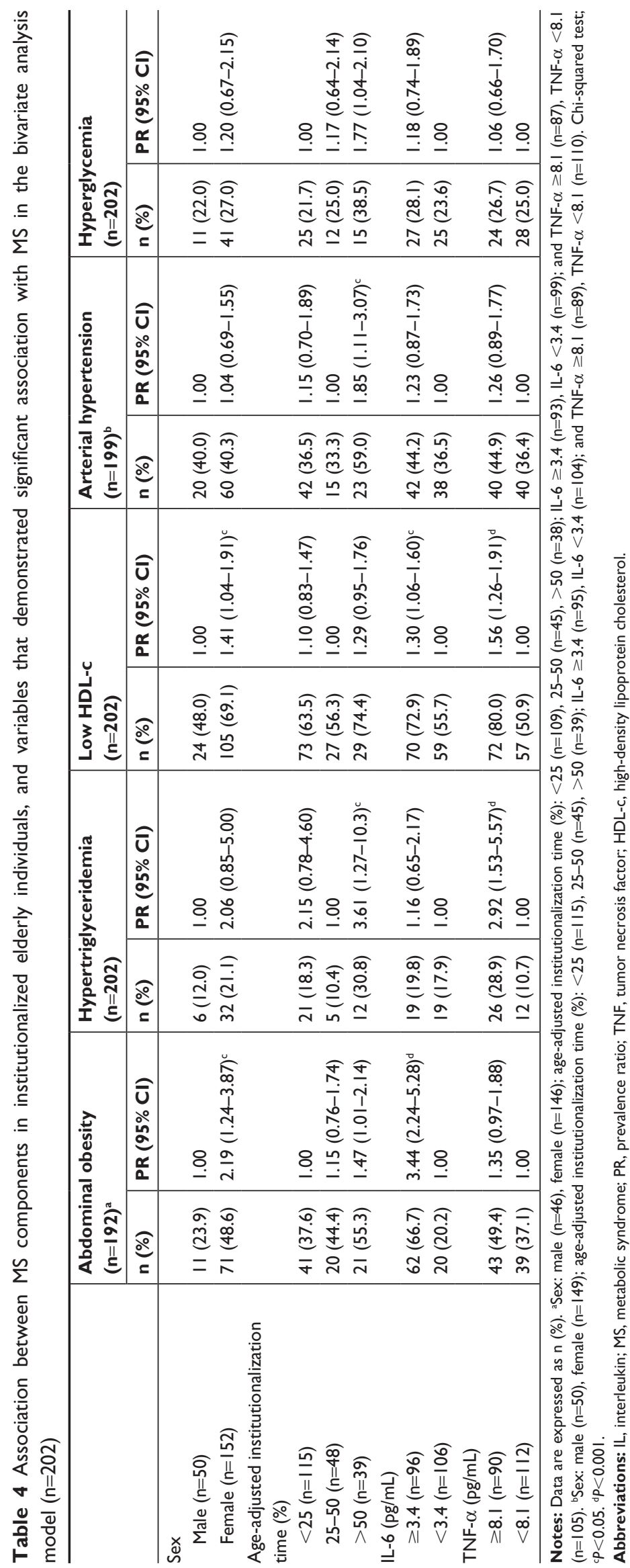


Table 5 Multivariate model including variables associated with MS with $P$-value $<0.20$ in the bivariate analysis $(n=20 \mathrm{I})$

\begin{tabular}{|c|c|c|c|c|}
\hline \multirow[t]{2}{*}{ Variables } & \multicolumn{2}{|c|}{ Variable category } & \multirow[t]{2}{*}{ Adjusted PR $(95 \% \mathrm{Cl})$} & \multirow[t]{2}{*}{$P$-value ${ }^{a}$} \\
\hline & Reference & Predictive & & \\
\hline $\begin{array}{l}\text { Sex } \\
\text { Age-adjusted } \\
\text { institutionalization time (\%) }\end{array}$ & $\begin{array}{l}\text { Male } \\
25 \%-50 \%\end{array}$ & $\begin{array}{l}\text { Female } \\
>50 \%\end{array}$ & $\begin{array}{l}2.16(1.04-4.49) \\
2.38(1.46-3.88)\end{array}$ & $\begin{array}{l}0.039 \\
0.001\end{array}$ \\
\hline Dietary components ${ }^{\mathrm{b}}$ & Group 2 & Group 4 & $1.85(1.11-3.10)$ & 0.019 \\
\hline IL-6 (pg/mL) & $<3.4$ & $\geq 3.4$ & $2.01(1.21-3.32)$ & 0.007 \\
\hline TNF- $\alpha(p g / m L)$ & $<8.1$ & $\geq 8.1$ & $1.70(1.05-2.77)$ & 0.032 \\
\hline
\end{tabular}

Notes: Data are expressed as $\mathrm{n}(\%)$. ${ }^{\mathrm{a}} \mathrm{C}$ hi-squared test. ${ }^{\mathrm{b}} \mathrm{Group} 2$ : moderate energy, moderate fat, and low dietary fiber intake; Group 4: very high energy, very low fat, and high dietary fiber intake.

Abbreviations: IL, interleukin; MS, metabolic syndrome; PR, prevalence ratio; TNF, tumor necrosis factor.

free fatty acids, which stimulate the hepatic output of very low-density lipoprotein. Exchange of triglycerides from very low-density lipoprotein for cholesterol esters from HDL-c by the cholesterol ester transfer protein results in rapid clearance of HDL-c..$^{40}$

Despite the fact that most participants in the present study had age-adjusted institutionalization times $<25 \%$ of their elderly lifetime, the frequency of hypertriglyceridemia and arterial hypertension was higher in individuals with an age-adjusted time in a $\mathrm{NH}$ of $>50 \%$.

Health care needs of the institutionalized elderly in Brazil are multidimensional and include a decline in health aspects such as higher dependence to perform activities of daily living, upper limb motor difficulty, greater use of medications such as antidepressants, and onset of various diseases ${ }^{44}$ Low incentive to practice physical activity in $\mathrm{NH}$ can lead to health problems. ${ }^{1}$ Moreover, standardization of dietary practices, without considering individual needs, may contribute to nutritional deficiencies. In addition, cultural, social, and religious aspects have significant influence on food choices. ${ }^{45}$ Health problems prior to institutionalization and senescence can contribute to the development of MS. This syndrome may result from the interaction between nutritional status during fetal life and early childhood and nutritional status and lifestyle in adulthood, and these environmental conditions may enhance genetic predisposition to MS development in old age. ${ }^{40}$

The inflammatory profile associated with MS suggested by this study was verified based on the high IL- 6 concentrations in elderly individuals with abdominal obesity and low HDL-c. In addition, MS was associated with high TNF- $\alpha$ concentration; low HDL-c and hypertriglyceridemia were the components involved in this association. A previous study demonstrated associations between IL- 6 and all MS components; however, an association between MS and TNF- $\alpha$ was not observed ${ }^{46}$ These results can be interpreted in light of the following aspects: 1) low HDL-c concentrations derived from the inhibition of lipoprotein lipase activity by IL-6 and TNF- $\alpha$, and from the increase in endothelial lipase induced by IL- $6,{ }^{19,47} 2$ ) abdominal obesity is induced by IL-6 via suppression of adiponectin synthesis, ${ }^{48} 3$ ) hypertriglyceridemia is associated with reduced lipoprotein lipase expression, ${ }^{19}$ and 4) dyslipidemia results from the activation of nuclear factor kappa B by TNF- $\alpha .{ }^{48}$ It is also worth mentioning that MS, once established, can itself generate inflammation due to interaction between MS components and the inflammatory process. ${ }^{20}$

The statistical significance observed in the association between MS and sex, age-adjusted institutionalization time, IL-6, and TNF- $\alpha$ was confirmed by the multiple analyses model. In addition, the linear regression model pointed to a greater occurrence of MS in the group with a diet characterized by higher energy and dietary fiber and lower total fat intake. Excess calories in these individuals' diets can be attributed to excessive intake of carbohydrates, which can be caused by stress eating, or the attempt to reduce fat intake.

The recommendation of dietary restrictions has come under question, and it has been pointed out that the main effects observed upon substitution of fats, especially saturated fats, by carbohydrates are a decrease in total cholesterol, including LDL-c and HDL-c, and an increase in triglycerides. These consequences lead to a greater risk of obesity, diabetes, and MS. ${ }^{49}$ This hypothesis has been reinforced by confirming that carbohydrate intake was positively associated and fat intake was inversely associated with the incidence of MS in women..$^{50}$ Women were the predominant gender in our population. In addition, we certified the low intake of monounsaturated and polyunsaturated fats, which are involved with the mechanisms underlying MS. ${ }^{51}$ Unpublished data from our group on food intake in this same population indicates that cereals, rice, breads, and biscuits - foods with high energy and simple carbohydrate content - are among the 
ten foods most frequently consumed. In addition, use of high protein supplements by some elderly individuals may have contributed to a high intake of this macronutrient. Regarding fruits and vegetables, the intake was below the standards, with respect to the general population.

In this regard, the Group 4 diet does not represent an adequate diet due to its high energy content, possibly from high levels of simple carbohydrates and proteins. In addition, the low intake of total fat is not necessarily a positive feature, since elderly individuals, in general, have a lower intake of monounsaturated and polyunsaturated fats. Regarding dietary fiber, the "high" intake designation in the Group 4 diet does not necessarily imply intake above the recommended level, but a high intake relative those of the other groups.

Similar to our results, studies with institutionalized elderly individuals in other countries have indicated that risk of MS does not differ significantly by age, type of diet, and behavioral factors such as tobacco use, alcohol intake, and physical activity. ${ }^{11}$ There may be particular factors associated with the institutionalized elderly that justify these results. In the present study, almost all individuals had hs-CRP concentrations above normal, thus masking the possible contribution of this inflammatory biomarker to the occurrence of MS. High concentrations of hs-CRP may be related to high morbidity, ${ }^{19}$ which is one of the main factors responsible for institutionalization. ${ }^{1}$ Similarly, the low variability of carbohydrate and protein intake, which may be a reflection of the standardization of food practices in $\mathrm{NH},{ }^{45}$ may have contributed to the absence of a statistical association between MS and these macronutrients. In addition, although alcoholism and smoking are known risk factors for $\mathrm{MS},{ }^{8}$ practices in the NH such as prohibiting smoking and alcohol consumption may have contributed to the fact that these aspects were not associated with MS in this population.

The limitations of this study include the difficulty of establishing a causal relationship among the variables due to the transversal design. Thus, we emphasize the importance of confirming our data prospectively in future studies. Furthermore, the absence of a control group of noninstitutionalized elderly individuals would allow for a greater understanding of the impact of institutionalization on MS. The study population composed of institutionalized elderly individuals is considered to be a strength of this research. The phenomenon of demographic and epidemiological transition, with progressive increases in the number of elderly people, chronic noncommunicable diseases (such as MS), and institutionalization, is occurring in Brazil and several other countries. However, MS in the specific population of institutionalized elderly individuals remains poorly described in the literature, with a dearth of data for the Brazilian population. Thus, the results of the present study can assist professionals in the expansion of health interventions for the institutionalized elderly population.

\section{Conclusion}

The occurrence of MS in institutionalized elderly individuals was higher in females, and in individuals with longer ageadjusted institutionalization time, higher concentrations of immunologic biomarkers, and a dietary intake consisting of higher energy and fiber and lower total fat. These results emphasize the importance of institutional care for elderly individuals due to the risk factors accumulated throughout their lives. Understanding the frequency of and factors associated with MS, a potentially costly syndrome in terms of morbidity, mortality, and quality of life will enable the development of preventative and treatment interventions.

\section{Ethics approval and informed consent}

All procedures performed in studies involving human participants were in accordance with the ethical standards of the institutional and/or national research committee and with the 1964 Declaration of Helsinki and its later amendments or comparable ethical standards. The study was approved by the Research Ethics Committee of the Federal University of Rio Grande do Norte (UFRN; protocol 263/11; CAAE 0290.0.051.000 - 11). All participants or their guardians provided written informed consent.

\section{Acknowledgments}

The authors thank the cooperation provided by all the elderly individuals and nursing homes involved in this study. The authors also thank Ana Celly Souza dos Santos (in memoriam) for assistance in laboratory analyses. This research was supported by the Research Support Foundation of Rio Grande do Norte (Fundação de Apoio à Pesquisa do Rio Grande do Norte - FAPERN) and the National Council for Scientific and Technological Development (Conselho Nacional de Desenvolvimento Científico e Tecnológico - CNPq, Brazil; grant no 77228/2013). The Coordination for the Improvement of Higher Education Personnel (Coordenação de Aperfeiçoamento de Pessoal de Nível Superior - CAPES, Brazil) awarded the doctorate scholarship. 


\section{Author contributions}

MCS, KCL, and LFCP contributed to the design and development of the study. MCS, LPO, LCPL, TMAML, and ATOC were involved in acquisition of data. MCS, KCL, KCMSE, SCVCL, and LFCP analyzed data or performed statistical analysis. MCS, LFCP, and SESS wrote the first draft of the manuscript. All authors contributed to data analysis, drafting or revising the article, gave final approval of the version to be published, and agree to be accountable for all aspects of the work.

\section{Disclosure}

The authors report no conflicts of interest in this work.

\section{References}

1. Weening-Dijksterhuis E, de Greef MH, Scherder EJ, Slaets JP, van der Schans CP. Frail institutionalized older persons: a comprehensive review on physical exercise, physical fitness, activities of daily living, and quality-of-life. Am J Phys Med Rehabil. 2011;90(2):156-168.

2. Agência Nacional de Vigilância Sanitária. Resolução da Diretoria Colegiada - $\mathrm{RDC} \mathrm{n}^{\circ} 283$, de 26 de setembro de 2005. Regulamento Técnico que define normas de funcionamento para as Instituições de Longa Permanência para Idosos. 2005. [National Health Surveillance Agency. Resolution of the Collegiate Board of Directors - RCBD n 283, of September 26, 2005. Technical Regulation that defines norms of operation for Nursing Homes. 2005.]. Available from: http://portal. anvisa.gov.br/documents/10181/2718376/RDC_283_2005_COMP.pdf/ a38f2055-c23a-4eca-94ed-76fa43acb1df. Accessed June 20, 2018.

3. Cavalcante ML, Borges CL, Moura AM, Carvalho RE. Indicators of health and safety among institutionalized older adults. Rev Esc Enferm USP. 2016;50(4):602-609.

4. Nevajda B, Havelka-Mestrović A, Bilić M, et al. Prevalence of the metabolic syndrome in the old institutionalized people in Zagreb, Croatia. Coll Antropol. 2013;37(1):203-206.

5. Expert Panel on Detection, Evaluation, and Treatment of High Blood Cholesterol in Adults. Executive summary of the third report of the National Cholesterol Education Program (NCEP) Expert Panel on Detection, Evaluation, and Treatment of High Blood Cholesterol in Adults (Adult Treatment Panel III). JAMA. 2001;285(19):2486-2497.

6. Sociedade Brasileira de Hipertensão, Sociedade Brasileira de Cardiologia, Sociedade Brasileira de Endocrinologia e Metabologia, Sociedade Brasileira de Diabetes, Associação Brasileira para Estudos da Obesidade. I Diretriz Brasileira de Diagnóstico e Tratamento da Síndrome Metabólica [I Brazilian Guidelines on Diagnosis and Treatment of Metabolic Syndrome]. Arq Bras Cardiol. 2005;84(Suppl 1):S1-S28. Portuguese.

7. American Diabetes Association. Diagnosis and classification of diabetes mellitus. Diabetes Care. 2015;38(Suppl 16):S8-S16.

8. Vieira EC, Peixoto MR, Silveira EA. Prevalence and factors associated with metabolic syndrome in elderly users of the Unified Health System. Rev Bras Epidemiol. 2014;17(4):805-817.

9. de Carvalho Vidigal F, Bressan J, Babio N, Salas-Salvadó J. Prevalence of metabolic syndrome in Brazilian adults: a systematic review. BMC Public Health. 2013;13:1198.

10. Fogal AS, Ribeiro AQ, Priore SE, Franceschini SCC. Prevalência de síndrome metabólica em idosos: uma revisão sistemática [Prevalence of metabolic syndrome in the elderly: A systematic review]. RASBRAN. 2014;6:29-35. Portuguese.

11. Sinha N, Bhattacharya A, Deshmukh PR, Panja TK, Yasmin S, Arlappa N. Metabolic syndrome among elderly care-home residents in southern India: A cross-sectional study. WHO South East Asia J Public Health. 2016;5(1):62-69.
12. Chiang PH, Liu CL, Lin MH, et al. Survival benefits of metabolic syndrome among older men aged 75 years and over in Taiwan. $J$ Nutr Health Aging. 2012;16(6):520-524.

13. Chang $\mathrm{CH}$, Chen YM, Chuang YW, et al. Relationship between hyperuricemia (HUC) and metabolic syndrome (MS) in institutionalized elderly men. Arch Gerontol Geriatr. 2009;49(Suppl 2):S46-S49.

14. Chou YY, Sheu WH, Tang YJ, et al. Plasminogen activator inhibitor type 1 (PAI-1) is a valuable biomarker for predicting the metabolic syndrome (MS) in institutionalized elderly residents in Taiwan. Arch Gerontol Geriatr. 2009;49(Suppl 2):S41-S45.

15. Pemminati S, Adhikari P, Pai MR, Pathak R. Metabolic syndrome among inmates of a 'home for aged' using IDF 2005 criteria. Nepal Med Coll J. 2009;11(1):31-33.

16. Nasution IR, Setiati S, Trisnohadi HB, Oemardi M. Insulin resistance and metabolic syndrome in elderly women living in nursing homes. Acta Med Indones. 2006;38(1):17-22.

17. Tran BT, Jeong BY, Oh JK. The prevalence trend of metabolic syndrome and its components and risk factors in Korean adults: results from the Korean National Health and Nutrition Examination Survey 2008-2013. BMC Public Health. 2017;17(1):71.

18. Al-Rubeaan K, Bawazeer N, Al Farsi Y, et al. Prevalence of metabolic syndrome in Saudi Arabia - a cross sectional study. BMC Endocr Disord. 2018;18(1):16.

19. Volp ACP, Alfenas RCG, Costa NMB, Minim VPR, Stringueta PC, Bressan J. Capacidade dos biomarcadores inflamatórios em predizer a síndrome metabólica. [Inflammation biomarkers capacity in predicting the metabolic syndrome]. Arq Bras Endocrinol Metabol. 2008; 52(3):537-549.

20. Ostan R, Bucci L, Cevenini E, et al. Metabolic syndrome in the offspring of centenarians: focus on prevalence, components, and adipokines. Age. 2013;35(5):1995-2007.

21. Rocha FL, Melo RLP, Menezes TN; Universidade Estadual da Paraíba, Brazil. Factors associated with metabolic syndrome among the elderly in the northeast of Brazil. Rev Bras Geriatr Gerontol. 2016;19(6):978-986.

22. Pérez-Tasigchana RF, León-Muñoz LM, Lopez-Garcia E, et al. Metabolic syndrome and insulin resistance are associated with frailty in older adults: a prospective cohort study. Age Ageing. 2017;46(5):807-812.

23. Assuncao N, Sudo FK, Drummond C, de Felice FG, Mattos P. Metabolic syndrome and cognitive decline in the elderly: a systematic review. PLoS One. 2018;13(3):e0194990.

24. Wiltink J, Michal M, Jünger C, et al. Associations between degree and sub-dimensions of depression and metabolic syndrome (MetS) in the community: results from the Gutenberg Health Study (GHS). BMC Psychiatry. 2018;18(1):114.

25. Estatuto do Idoso - Lei 10741/03 | Lei no 10.741 , de $1^{\circ}$ de outubro de 2003. [The Statute of Elderly - Law n ${ }^{\circ} 10,741$, of October 1st, 2003]. Available from: http://www.planalto.gov.br/ccivil_03/leis/2003/ L10.741.htm. Accessed June 20, 2018.

26. Sales MC, de Oliveira LP, de Araújo Cabral NL, et al. Plasma zinc in institutionalized elderly individuals: Relation with immune and cardiometabolic biomarkers. J Trace Elem Med Biol. 2018;50:615-621.

27. Jerez-Roig J, de Brito Macedo Ferreira LM, Torres de Araújo JR, Costa Lima K. Functional decline in nursing home residents: A prognostic study. PLoS One. 2017;12(5):e0177353.

28. World Health Organization. Physical status: the use and interpretation of anthropometry. Report of a WHO Expert Committee 1995. 1995. Available from: http://apps.who.int/iris/bitstream/10665/37003/1/ WHO_TRS_854.pdf. Accessed May 20, 2018.

29. Sociedade Brasileira de Cardiologia (SBC), Sociedade Brasileira de Hipertensão (SBH), Sociedade Brasileira de Nefrologia (SBN). VI Diretrizes Brasileiras de Hipertensão [VI Brazilian Guidelines on Hypertension]. Arq Bras Cardiol. 2010;95:1-51.

30. Cruz ATR, Souza JMP, Philippi ST. Avaliação da concordância dos métodos de pesagem direta de alimentos em creches - São Paulo - Brasil [Measuring agreement in Direct Food Weighing Methods in child care centers in São Paulo - Brazil]. Rev Bras Epidemiol. 2003;6:220-226. Portuguese. 
31. Institute of Medicine. Dietary Reference Intakes for Energy, Carbohydrate, Fiber, Fat, Fatty Acids, Cholesterol, Protein, and Amino Acids. Food and Nutrition Board. Washington, DC: National Academy Press; 2002.

32. Baum J, Kim I-Y, Wolfe R. Protein consumption and the elderly: what is the optimal level of intake? Nutrients. 2016;8(6):E359.

33. Espelt A, Marí-dell'olmo M, Penelo E, Bosque-Prous M. Applied prevalence ratio estimation with different regression models: an example from a cross-national study on substance use research. Adicciones. 2016; 29(2):105-112.

34. Miettinen OS, Cook EF. Confounding: essence and detection. Am J Epidemiol. 1981;114(4):593-603.

35. Willett WC. Nutritional Epidemiology. 3rd ed. Oxford: Oxford University Press; 2012.

36. Nusser SM, Carriquiry AL, Dodd KW, Fuller WA. A semiparametric transformation approach to estimating usual daily intake distributions. J Am Stat Assoc. 1996;91(436):1440-1449.

37. Rigo JC, Vieira JL, Dalacorte RR, Reichert CL. Prevalence of metabolic syndrome in an elderly community: comparison between three diagnostic methods. Arq Bras Cardiol. 2009;93(2):85-91.

38. Akbulut G, Köksal E, Bilici S, et al. Metabolic syndrome (MS) in elderly: a cross sectional survey. Arch Gerontol Geriatr. 2011;53(3): e263-e266.

39. Rojas R, Aguilar-Salinas CA, Jiménez-Corona A, et al. Metabolic syndrome in Mexican adults: results from the National Health and Nutrition Survey 2006. Salud Publica Mex. 2010;52(Suppl 1):S11-S18.

40. Samson SL, Garber AJ. Metabolic syndrome. Endocrinol Metab Clin North Am. 2014;43(1):1-23.

41. Gadelha AB, Myers J, Moreira S, Dutra MT, Safons MP, Lima RM. Comparison of adiposity indices and cut-off values in the prediction of metabolic syndrome in postmenopausal women. Diabetes Metab Syndr. 2016;10(3):143-148.

42. Lovre D, Lindsey SH, Mauvais-Jarvis F. Effect of menopausal hormone therapy on components of the metabolic syndrome. Ther Adv Cardiovasc Dis. 2016;11(1):33-43.
43. Orgaz Gallego MP, Bermejo López P, Tricio Armero MA, Abellán Alemán J, Solera Albero J, Tárraga López PJ. Metabolic syndrome and its components in Spanish postmenopausal women. Nutr Hosp. 2015; 32(2):656-666.

44. Menezes RL, Bachion MM, Souza JT, Nakatani AYK. Estudo longitudinal dos aspectos multidimensionais da saúde de idosos institucionalizados [Longitudinal study of multidimensional aspects of the health of institutionalized elderly]. Rev Bras Geriatr Gerontol. 2011;14: 485-496. Portuguese.

45. Oliveira RBA, Veras RP, Prado SD. A alimentação de idosos sob vigilância: experiências no interior de um asilo [Food for elderly under surveillance: experiences inside an asylum]. Rev Bras Geriatr Gerontol. 2010;13(3):413-423. Portuguese.

46. Hung J, Mcquillan BM, Chapman CM, Thompson PL, Beilby JP. Elevated interleukin-18 levels are associated with the metabolic syndrome independent of obesity and insulin resistance. Arterioscler Thromb Vasc Biol. 2005;25(6):1268-1273.

47. Zuliani G, Volpato S, Blè A, et al. High interleukin-6 plasma levels are associated with low HDL-C levels in community-dwelling older adults: the InChianti study. Atherosclerosis. 2007;192(2):384-390.

48. Fuentes E, Fuentes F, Vilahur G, Badimon L, Palomo I. Mechanisms of chronic state of inflammation as mediators that link obese adipose tissue and metabolic syndrome. Mediators Inflamm. 2013;2013:136584.

49. Siri-Tarino PW, Chiu S, Bergeron N, Krauss RM. Saturated fats versus polyunsaturated fats versus carbohydrates for cardiovascular disease prevention and treatment. Annu Rev Nutr. 2015;35:517-543.

50. Park S, Ahn J, Kim NS, Lee BK. High carbohydrate diets are positively associated with the risk of metabolic syndrome irrespective to fatty acid composition in women: the KNHANES 2007-2014. Int J Food Sci Nutr. 2017;68(4):479-487.

51. Wang Q, Afshin A, Yakoob MY, et al. Impact of nonoptimal intakes of saturated, polyunsaturated, and trans fat on global burdens of coronary heart disease. J Am Heart Assoc. 2016;5(1):e002891.
Clinical Interventions in Aging

\section{Publish your work in this journal}

Clinical Interventions in Aging is an international, peer-reviewed journal focusing on evidence-based reports on the value or lack thereof of treatments intended to prevent or delay the onset of maladaptive correlates of aging in human beings. This journal is indexed on PubMed Central, MedLine,

\section{Dovepress}

CAS, Scopus and the Elsevier Bibliographic databases. The manuscript management system is completely online and includes a very quick and fair peer-review system, which is all easy to use. Visit http://www.dovepress. com/testimonials.php to read real quotes from published authors. 